\title{
Antimalarial Properties of $n-3$ and $n-6$ Polyunsaturated Fatty Acids: In Vitro Effects on Plasmodium falciparum and In Vivo Effects on P. berghei
}

Lakshmi M. Kumaratilake, ${ }^{\star}$ Brenton S. Robinson, ${ }^{\star}$ Antonio Ferrante, ${ }^{\star}$ and Alf Poulos ${ }^{\star}$

*Department of Immunology and University of Adelaide Department of Paediatrics; and ${ }^{\ddagger}$ Department of Chemical Pathology, Adelaide Children's Hospital, South Australia 5006, Australia

\begin{abstract}
The polyunsaturated fatty acids docosahexaenoic acid $\left(\mathrm{C}_{22: 6, \mathrm{n}-3}\right)$, eicosapentaenoic acid, arachidonic acid, and linoleic acid caused marked in vitro growth inhibition of Plasmodium falciparum, assessed by a radiometric assay. In contrast, negligible parasite killing was seen with oleic acid or docosanoic acid. Parasite killing was significantly increased when oxidized forms of polyunsaturated fatty acids were used. Antioxidants greatly reduced the fatty acid-induced killing. Mice infected with $P$. berghei and treated for $4 \mathrm{~d}$ with $\mathrm{C}_{22: 6, \mathrm{~m}-3}$ showed marked reduction in parasitemia. The anemia associated with the infection was also alleviated by treatment with $C_{22: 6, n-3}$. The data provide new information that could be explored in order to develop new strategies in malaria treatment. (J. Clin. Invest. 1992. 89:961-967.) Key words: anemia $\bullet$ antioxidants $\bullet$ crisis forms • fish oil • parasite growth inhibition
\end{abstract}

\section{Introduction}

Over half of the world's population is at risk from malaria, involving some 100 countries, 500 million acute infections, and over 1 million deaths recorded per year $(1,2)$. As a whole, this situation has shown little improvement in the last 15 years. Vaccine development is proving lengthy and complex, and drug development continues to be a major goal in that the toxicity-related side effects of present chemotherapy render it only partially satisfactory and drug resistance is rife.

In the hope of developing unique strategies for the treatment of malaria, some investigations have concentrated on attempts to identify the natural molecules responsible for "crisis" formation (deranged development and degeneration of in-

Data from parts of this paper were presented at the Fourth International Congress on Malaria and Babesiosis, August 1991, in Rio de Janeiro, Brazil, August 1991.

Address reprint requests to L. M. Kumaratilake, Department of Immunology, Adelaide Children's Hospital, North Adelaide, South Australia 5006, Australia.

Received for publication 25 July 1991 and in revised form 25 October 1991

1. Abbreviations used in this paper: BHT, butylated hydroxytoluene; $\mathrm{C}_{18: 1, \mathrm{n}-9}$, oleic acid; $\mathrm{C}_{18: 2, \mathrm{n}-6}$, linoleic acid; $\mathrm{C}_{20: 4, \mathrm{n}-6}$, arachidonic acid; $\mathrm{C}_{20: 5, \mathrm{n}-3}$, eicosapentaenoic acid; $\mathrm{C}_{22: 0}$, docosanoic acid; $\mathrm{C}_{22: 6, \mathrm{n}-3}$, docosahexaenoic acid; DPPC, DL- $\alpha$-dipalmitoyl phosphatidylcholine; RBC and PRBC, red blood cells and parasitized RBC, respectively; TNF $\alpha$, tumor necrosis factor $\alpha$.

J. Clin. Invest.

(c) The American Society for Clinical Investigation, Inc.

0021-9738/92/03/0961/07 \$2.00

Volume 89, March 1992, 961-967 traerythrocytic malarial parasites; references 3-10). However, crisis-inducing factors still remain ill defined (11). This paper describes the in vitro killing of intraerythrocytic forms of Plasmodium falciparum and the in vivo killing of $P$. berghei in mice by polyunsaturated fatty acids. The finding has the potential to be exploited for therapeutic purposes and may help explain mechanisms of crisis formation in vivo. Some of these polyunsaturated fatty acids are released by phagocytic leucocytes and/ or may be acquired through normal diet or dietary supplements.

\section{Methods}

Parasite. Six isolates of $P$. falciparum were maintained under in vitro conditions in group $\mathrm{O}^{+}$human red blood cells (RBC) ${ }^{1}$ in RPMI 1640 medium (Cytosystems Pty. Ltd., Sydney, Australia) supplemented with $10 \%$ heat-inactivated group $\mathrm{AB}^{+}$serum, as described previously $(12,13)$. Experiments were performed with synchronized and nonsynchronized cultures at $10^{8} \mathrm{RBC} / \mathrm{ml}$ with $3-5 \%$ parasitemia.

Mice. Female 6-8-wk-old BALB/c mice were used. They were fed with industrial mouse pellets (Milling Industries, Adelaide, South Australia) and water ad lib.

Fatty àcids. Docosahexaenoic acid $\left(\mathrm{C}_{22: 6, \mathrm{n}-3}\right)$, docosahexaenoic acid methyl ester $\left(C_{22: 6, n-3}\right.$ methyl ester $)$, eicosapentaenoic acid $\left(C_{20: 5, n-3}\right)$, arachidonic acid $\left(\mathrm{C}_{20: 4, \mathrm{n}-6}\right)$, linoleic acid $\left(\mathrm{C}_{18: 2, \mathrm{n}-6}\right)$, oleic acid $\left(\mathrm{C}_{18: 1, \mathrm{n}-\mathrm{9}}\right)$, docosanoic acid $\left(\mathrm{C}_{22: 0}\right)$, and DL- $\alpha$-dipalmitoyl phosphatidylcholine (DPPC) were obtained from Sigma Chemical Co. (St. Louis, MO). Lipids were dissolved in redistilled chloroform $(10-50 \mathrm{mg} / 5 \mathrm{ml})$ and stored under $\mathrm{N}_{2}$ at $-20^{\circ} \mathrm{C}$. Thin-layer chromatography indicated that the lipids were of high purity. Mixed fatty acid-DPPC micelles were prepared as follows. Fatty acid $(8,32$, or $80 \mu \mathrm{g}$ ) and DPPC (fourfold the amount of fatty acid) were dispensed into $10-\mathrm{ml}$ glass tubes and the solvent was evaporated under $\mathrm{N}_{2} .2 \mathrm{ml}$ of RPMI 1640 medium was added and the mixture was sonicated for 2 min with an ultrasonic processor (model W-225; Heat Systems-Ultrasonics, Inc., Farmingdale, NY) with $40 \%$ duty cycle and output setting 4 . The lipid sonicates were clear under these conditions. 50- $\mu$ l aliquots of each sonicate (containing 4,16 , or $40 \mu \mathrm{g} / \mathrm{ml}$ fatty acid) were used for assays unless stated otherwise.

Growth inhibition assay. This was carried out as described previously $(12,13)$ with the following modifications. Experiments were conducted in 96-well flat-bottomed microdilution plates (Linbro, Flow Laboratories, Inc., McLean, VA), comparing three different treatment groups. $50 \mu \mathrm{l} P$. falciparum-infected RBC were mixed with $50 \mu \mathrm{l}$ of either fatty acids $(40 \mu \mathrm{g} / \mathrm{ml})$, diluent (DPPC), or malaria medium. The plates were incubated for $2 \mathrm{~h}$ at $37^{\circ} \mathrm{C}$ in $5 \% \mathrm{CO}_{2}$ in air. Then the wells were pulsed with $1 \mu \mathrm{Ci}$ of $\left[{ }^{3} \mathrm{H}\right]$ hypoxanthine (Amersham Corp., Arlington Heights, IL) in $50 \mu$ l of RPMI 1640 medium and incubated for a further $18 \mathrm{~h}$ at $37^{\circ} \mathrm{C}$ in $5 \% \mathrm{CO}_{2}$ in air. Individual well contents were then collected using a semiautomated sample harvester (Titertek, Flow Laboratories, Sydney, Australia) and the $\left[{ }^{3} \mathrm{H}\right]$ hypoxanthine incorporation was measured in a liquid scintillation counter (model LS 3801; Beckman Instruments, Carlsbad, CA). Percent growth inhibition of the parasite was calculated by the following formula: percent inhibition $=[(\mathrm{dpm}$ of parasite in diluent $)-(\mathrm{dpm}$ of parasite incubated with fatty 
acids $) \times 100] /(\mathrm{dpm}$ of parasite in diluent $)$, where $\mathrm{dpm}$ is disintegrations per minute.

Effects of different concentrations of fatty acids on normal and infected $R B C$. RBC collected from healthy volunteers were suspended in malaria medium in two culture flasks, and the parasite was inoculated into one. After $3 \mathrm{~d}$ of culture, both the normal RBC and parasitized RBC (PRBC) were exposed to various concentrations of fatty acids (4, 16 , and $40 \mu \mathrm{g} / \mathrm{ml}$ at $50 \mu \mathrm{l} / 5 \times 10^{5} \mathrm{RBC}$ ). The supernatants were collected from the wells containing normal or PRBC and the hemoglobin release was determined as described previously (14). Parasite growth inhibition was studied by radiometric assay. Morphology of RBC and PRBC was studied in thin smears.

Effects of fish oil on growth of P. falciparum. The effects of fish oil (Maxepa, Duncan, Flockhart, UK), containing the triglycerides of $18 \%$ wt/wt $\mathrm{C}_{20: 5, \mathrm{n}-3}$ and $12 \% \mathrm{wt} / \mathrm{wt}$ of $\mathrm{C}_{22: 6, \mathrm{n}-3}$, on $P$. falciparum were examined using the growth inhibition assay described above. $50 \mu \mathrm{l}$ of fish oil at concentrations of $4,16,20$, and $40 \mu \mathrm{g} / \mathrm{ml}$ incorporated into DPPC was added to $50 \mu \mathrm{l}$ of RBC with 3-5\% parasitemia.

Effects of oxidized fatty acids on growth of $P$. falciparum. $\mathrm{C}_{22: 6, \mathrm{n}-3}$ and $\mathrm{C}_{20: 4, \mathrm{n}-6}$ fatty acids were dispensed into $10-\mathrm{ml}$ glass tubes and the solvent was evaporated under $\mathrm{N}_{2}$. The dried residues were autooxidized by exposure to the air at room temperature for 2-4 $\mathrm{d}$. Thin-layer chromatography indicated that $>95 \%$ of the parent fatty acids had been oxidized by this procedure. Products included monohydroperoxy derivatives and other more polar oxygenated compounds (15). These oxidized fatty acids were compared with freshly prepared fatty acids using the radiometric growth inhibition assay.

Effects of antioxidants, catalase, and SOD on fatty acid effects. In an 18-well microdilution plate (Linbro), $500 \mu l$ PRBC were incubated with equal volumes of $(a)$ butylated hydroxytoluene (BHT) $(60 \mu \mathrm{M}$ in $0.5 \%$ ethanol; Sigma Chemical Co.), (b) DL- $\alpha$-tocopherol (vitamin E; $40 \mu \mathrm{M}$ in $0.5 \%$ ethanol; Sigma Chemical Co.), (c) SOD from bovine RBC ( $1 \mathrm{mg} / \mathrm{ml}$; Sigma Chemical Co.), (d) catalase from bovine liver (1 $\mathrm{mg} / \mathrm{ml}$; Sigma Chemical Co.), (e) $0.5 \%$ ethanol (diluent of BHT and vitamin $\mathrm{E})$, and $(f)$ malaria medium, then incubated for $18 \mathrm{~h}$ in a candle jar at $37^{\circ} \mathrm{C}(16)$. After incubation, blood smears were prepared and stained and parasitemias were determined. The parasite culture contents were centrifuged; the supernatant was replaced with an equal volume of malaria medium or with medium containing antioxidants, catalase, and SOD; and the PRBC pellet was resuspended. PRBC were dispensed into 96-well microdilution plates and were reacted with the fatty acids $\mathrm{C}_{22: 6, \mathrm{n}-3}$ and $\mathrm{C}_{20: 4, \mathrm{n}-6}$ for $2 \mathrm{~h}$. Parasite growth inhibition was studied using the radiometric assay.

Comparison of use of albumin and DPPC micelles to incorporate fatty acids. Mixed fatty acid-DPPC micelles were compared with fatty acids $(40 \mu \mathrm{g} / \mathrm{ml})$ sonicated in the presence of $3 \mathrm{mg} / \mathrm{ml}$ fatty acid-free albumin (Sigma Chemical Co.) for anti-P. falciparum activity by using the radiometric assay.

Effects of the fatty acid $C_{22: 6, n-3}$ on $P$. berghei. Virulent $P$. bergheiinfected blood stored under liquid $\mathrm{N}_{2}$ was used to infect one mouse by intraperitoneal inoculation, $7 \mathrm{~d}$ before the experiment. $2 \mathrm{~d}$ before the experiment, $\sim 300 \mu \mathrm{l}$ of blood was taken from the retroorbital plexus of the infected mouse and RBC level was adjusted to $10^{7} / \mathrm{ml}$ in saline. The mice used in experiments were injected with $\sim 5 \times 10^{6} \mathrm{RBC} /$ mouse i.p.

On the day of the experiment, the mice were randomly divided into groups of five, and initial parasitemia was determined in blood smears. Fatty acid $\mathrm{C}_{\text {22:6,n-3 }}$ DPPC micelles were prepared (as described above) just before administration. Three experiments were conducted. In each, group 1 received, as a $400-\mu \mathrm{l}$ i.p. of $(10 \mu \mathrm{g}), \mathrm{C}_{22: 6, \mathrm{n}-3}$; group 2, 40 $\mu \mathrm{g}$ of DPPC; and group 3, saline. All groups were injected three times/d (9:30 a.m., 12:30 p.m., and 3:30 p.m.) for 4 d. Blood smears were prepared at 9:00 a.m. and 12:00 noon daily. On the 5th $d$ the mice were bled for hematocrit determination.

Comparison of $C_{22: 6, n-3}$ with $C_{20: 4, n-6}$ and $C_{22: 0}$ fatty acids. The above fatty acids were freshly prepared in DPPC as described above and mice were treated with $10 \mu \mathrm{g} / 400 \mu \mathrm{l}$ i.p., three times/d for $4 \mathrm{~d}$. Blood smears were prepared and parasitemia determined.
Determination of parasitemia. Giemsa-stained thin blood smears were examined under $\times 1,000$ magnification and PRBC were counted in $\geq 10$ different areas of the smear. A minimum of 1,000 (very heavy infections) to 10,000 (low to moderate infections) $\mathrm{RBC}$ were studied/ mouse at a time, and \%PRBC was expressed as parasitemia.

Statistical analysis. The results were compared by the paired twotailed Student's $t$ test.

\section{Results}

Effects of polyunsaturated fatty acids on P. falciparum in vitro. Fig. 1 summarizes the effects of fatty acids on the growth of asexual blood stages of $P$. falciparum. Treatment of parasites with $\mathrm{C}_{22: 6, \mathrm{n}-3}, \mathrm{C}_{20: 5, \mathrm{n}-3}, \mathrm{C}_{20: 4, \mathrm{n}-6}$, and $\mathrm{C}_{18: 2, \mathrm{n}-6}$ resulted in marked inhibition of $P$. falciparum growth. However, the fatty acids $\mathrm{C}_{\text {18:1,n-9 } 9}$ and $\mathrm{C}_{22: 0}$ had very little effect. The highest antimalarial activity was always seen with $\mathrm{C}_{22: 6, \mathrm{n}-3}(76 \pm 3.3 \%$ growth inhibition). The methyl ester of this fatty acid was just as effective $(71 \pm 4.3 \%)$. Similar results were obtained when fatty acids were delivered in either albumin or DPPC (data not presented). The antimalarial activity of the fatty acids was concentration dependent (Fig. 2). Within the range of 4 to $40 \mu \mathrm{g} / \mathrm{ml}$, the fatty acids did not induce hemolysis of parasitized or normal RBC as assessed by hemoglobin release and by morphological criteria. At these concentrations, DPPC was not toxic to $P$. falciparum and $\left[{ }^{3} \mathrm{H}\right]$ hypoxanthine incorporation was not affected by the presence of the phospholipid.

Microscopic examination of fatty acid-treated P. falciparum. Microscopic examination showed that parasites exposed to polyunsaturated fatty acids for $18 \mathrm{~h}$ underwent degen-

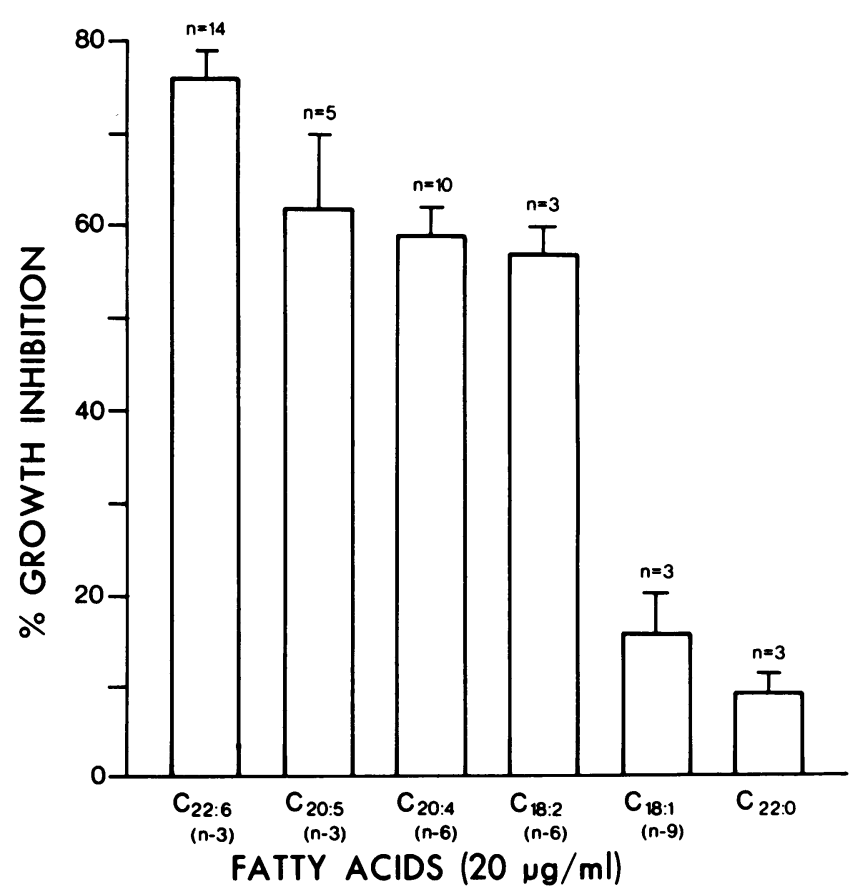

Figure 1. Effects of various fatty acids on growth inhibitions of $P$. falciparum. $50 \mu$ l of PRBC $\left(1 \times 10^{8} / \mathrm{ml}, 2-5 \%\right.$ parasitemia $)$ was mixed with $50 \mu \mathrm{l}$ of fatty acids $(40 \mu \mathrm{g} / \mathrm{ml})$ and incubated for $2 \mathrm{~h}$, before adding $\left[{ }^{3} \mathrm{H}\right]$ hypoxanthine for assessing parasite growth inhibition after $18 \mathrm{~h}$ of incubation at $37^{\circ} \mathrm{C}$. The diluent, DPPC, did not induce any growth inhibition of the parasite. $n$, number of different experiments carried out with each fatty acid. Means \pm SEM are given. 


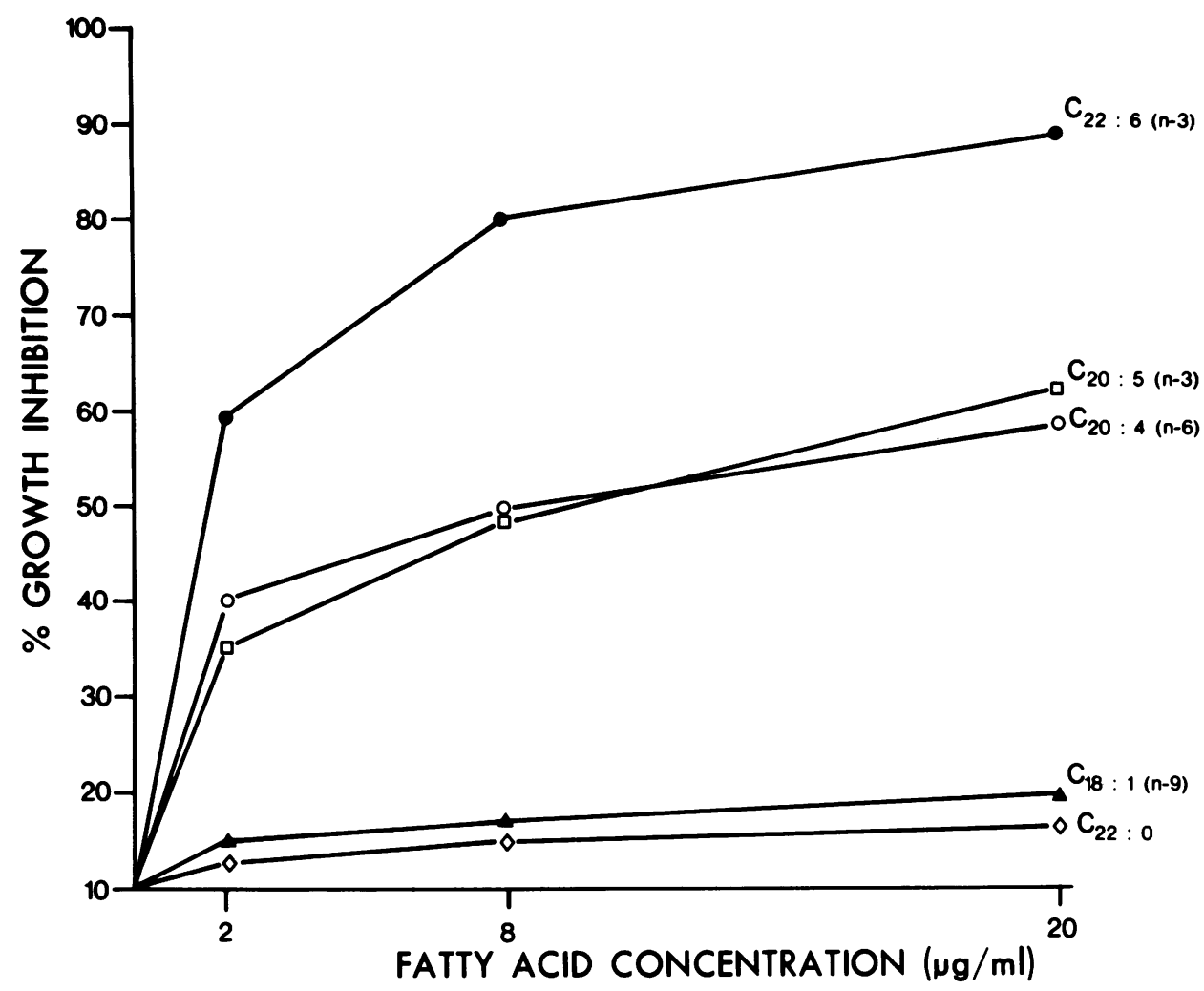

Figure 2. Concentration-related anti-P. falciparum activity of fatty acids. The diluent, DPPC, did not induce any growth inhibition of the parasite. eration and death (Fig. 3). We found that immature and mature schizonts were more susceptible to the fatty acid-induced effects than were ring forms. However, the majority of ring forms were also found to be degenerated. The dead parasites were removed from the parasitophorous vacuole through its orifice to the exterior of the $\mathrm{RBC}$. The fatty acid $\mathrm{C}_{22: 6, \mathrm{n}-3}$ caused $>90 \%$ death of $P$. falciparum. The survived parasites were in the ring form. $\mathrm{C}_{20: 4, \mathrm{n}-6}$ caused $80 \%$ death or degeneration of the parasite. In addition to rings, a small percentage of schizonts also survived when treated with $\mathrm{C}_{20: 4, \mathrm{n}-6}$. In contrast, $\mathrm{C}_{22: 0^{-}}$ treated $P$. falciparum cultures were very similar to the parasite grown in the absence of fatty acids.

Effects of fish oil. Fish oil compared with $40 \mu \mathrm{g} / \mathrm{ml} \mathrm{C}_{22: 6, \mathrm{n}-3}$ showed a much lower inhibition of the parasite growth. When PRBC were treated with $40 \mu \mathrm{g} / \mathrm{ml}$ of fish oil for $2 \mathrm{~h}$, the parasite inhibition was $20.5 \pm 8.5 \%$. However, when the interaction time

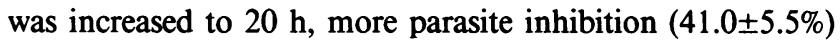
was observed.

Effects of oxidized fatty acids. The oxidized forms of these fatty acids showed increased activity against $P$. falciparum (Fig. 4). Oxidized $C_{22: 6, n-3}$ and $C_{20: 4, n-6}$ showed significantly more antiparasitic activity $(P<0.01)$ than the nonoxidized forms (Fig. 4). Antiparasitic effects were reduced by $\sim 50 \%$ if PRBC had been preincubated with BHT or vitamin E overnight, washed, and then exposed to the native fatty acids. Antiparasitic activity was reduced by $>70 \%$ when the preincubated PRBC were reacted with fatty acids in the presence of BHT and vitamin $\mathrm{E}$ (Fig. 4). The effects of polyunsaturated fatty acids were also greatly reduced if the PRBC were treated with SOD or catalase (Fig. 4). Ethanol (0.5\%), the diluent for some of these reducing reagents, had no effect on parasite growth.

Effects of polyunsaturated fatty acids on $P$. berghei infection in mice. Mice treated with the fatty acid vehicle DPPC showed parasitemias similar to those of mice that received saline (Fig. 5). The parasitemia increased steadily in these mice. $6 \mathrm{~d}$ after infection, these mice showed a 60 -fold increase in parasitemia (Fig. 5). After a single injection of the fatty acid $C_{22: 6, n-3}$, the parasitemia was significantly reduced from $1.65 \pm 0.40$ to $0.25 \pm 0.04 \%(P<0.001$; Fig. 5). Throughout the course of the treatment, the parasitemia was maintained at a lower level than the initial parasitemia (Fig. 5). Compared with the mice that received DPPC or saline, the fatty acid-treated mice showed markedly lower parasitemia $(P<0.001)$. In the mice treated with DPPC or saline, the parasites grew rapidly, showing all different stages of the asexual and sexual stages. In contrast, in

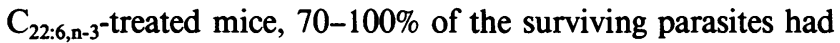
"restricted growth" and appeared as a "dot" form. $\mathrm{C}_{20: 4, \mathrm{n}-6}$ was similarly effective in reducing the parasitemia, but $\mathrm{C}_{22: 0}$ had no effect (data not presented).

Mice were examined for anemia. The hematocrit values for

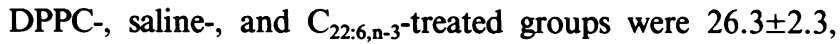
$25.9 \pm 2.5$, and $40.7 \pm 6.9$, respectively.

\section{Discussion}

The data demonstrate that fatty acids vary in ability to cause growth inhibition of $P$. falciparum in culture. Whereas the polyunsaturated fatty acids $\mathrm{C}_{22: 6, \mathrm{n}-3}, \mathrm{C}_{20: 5, \mathrm{n}-3}, \mathrm{C}_{20: 4, \mathrm{n}-6}$, and $\mathrm{C}_{18: 2, \mathrm{n}-6}$ caused marked growth inhibition of the parasite, the monounsaturated and saturated fatty acids $C_{18: 1, n-9}$ and $C_{22: 0}$ had little effect. This result demonstrates that the antiplasmodial activity of the fatty acids is dependent in part on the degree of unsaturation (number of double bonds present). For example, the degree of inhibition induced by the $22-\mathrm{C}$ fatty acids was increased severalfold by the introduction of six double bonds into the molecule. Similarly, the addition of a single double bond into 

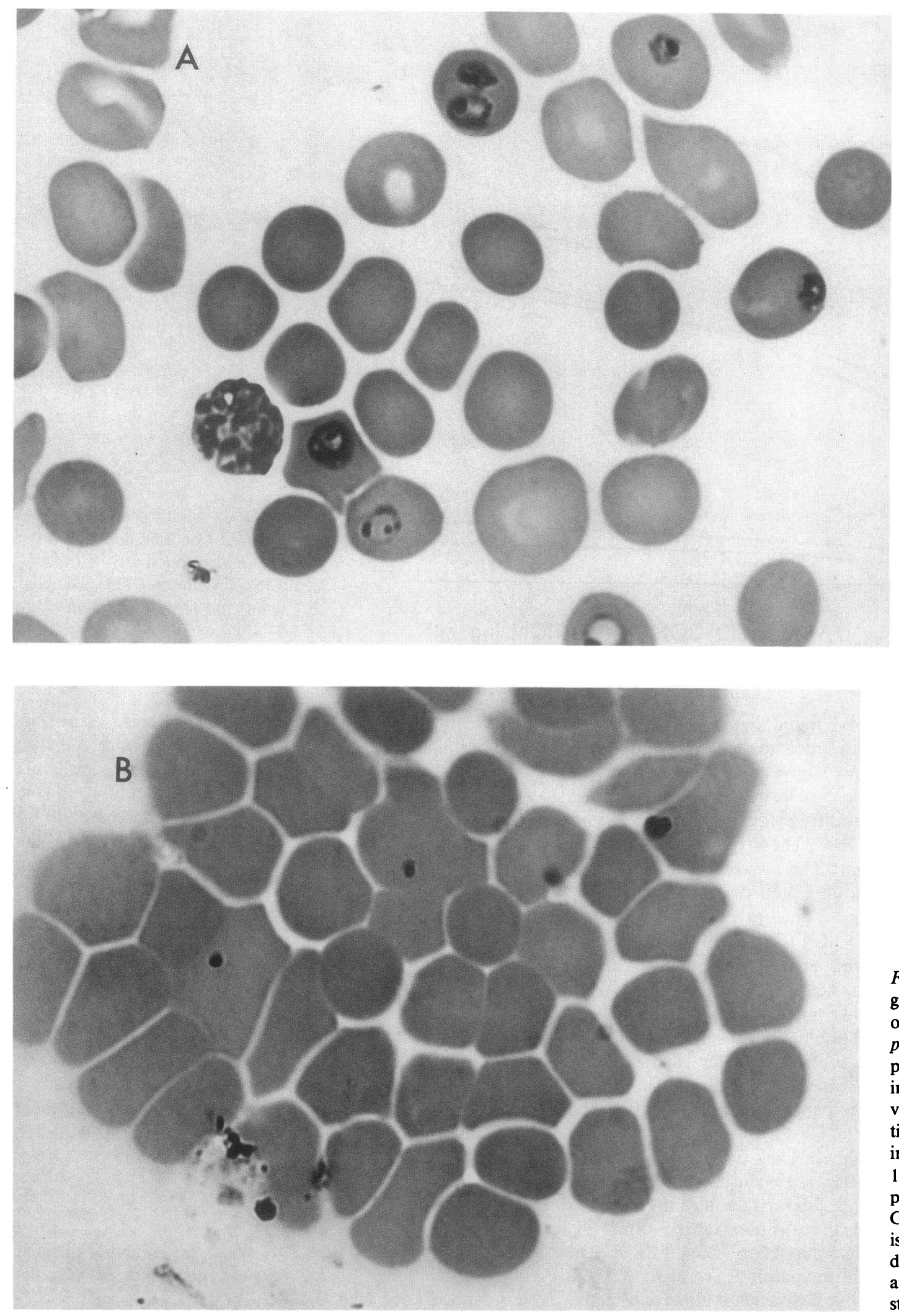

Figure 3. Photomicrographs showing the effects of $\mathrm{C}_{22: 6, \mathrm{n}-3}$ on P. falciparum. $(A)$ Normal morphology of $P$. falciparuminfected RBC showing various stages of maturation. $(B)$ The same culture incubated with $\mathrm{C}_{22: 6, \mathrm{n}-3}$ for $18 \mathrm{~h}$. Note that the cytoplasm does not absorb Giemsa stain, the nucleus is darkly stained and condensed, and the parasites are devoid of any normal structures.

the monounsaturated fatty acid $\mathrm{C}_{18: 1, \mathrm{n}-\mathrm{9}}$ more than tripled the parasiticidal effects of the molecules.

At the concentrations tested, the fatty acids were not toxic for either normal RBC or PRBC and did not induce hemolysis (determined biochemically). Similar results were observed between the fatty acids solubilized in DPPC or albumin, indicat- ing that binding of fatty acids to albumin in vivo is unlikely to inhibit their antimalarial activity.

Results of the in vivo experiments confirmed the antiplasmodial effects of polyunsaturated fatty acids. The fatty acids $\mathrm{C}_{22: 6, \mathrm{n}-3}$ and $\mathrm{C}_{20: 4, \mathrm{n}-6}$ were capable of inhibiting the growth of $P$. berghei in mice, but the saturated fatty acid $\mathrm{C}_{22: 0}$ had no effect 


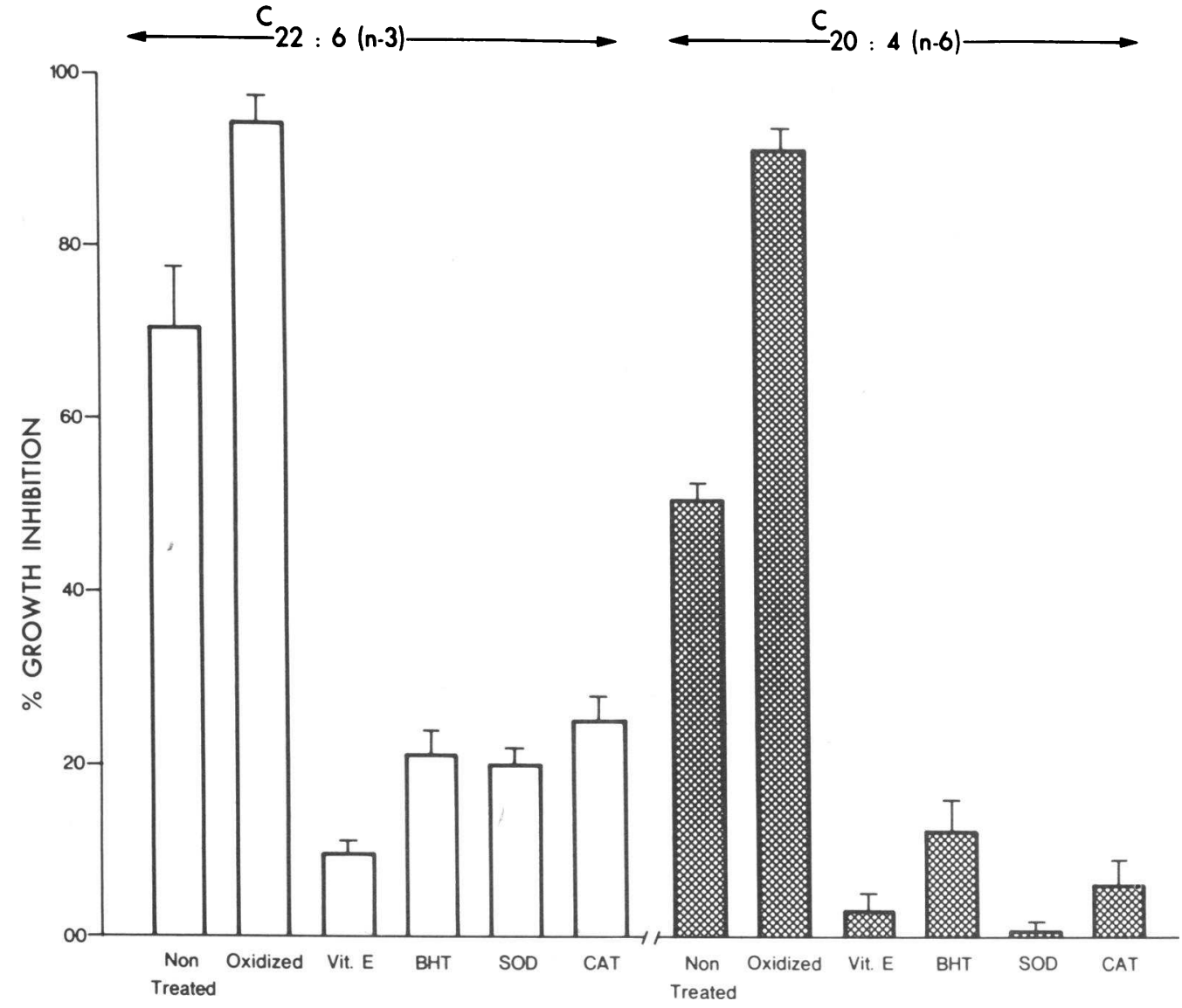

Figure 4. The effects of oxidized fatty acids or "antioxidants." The effects of oxidization of the fatty acids or treatment of PRBC with antioxidants (Vit. E, vitamin E; BHT, SOD; and CAT, catalase) on the ability of the fatty acids to damage $P$. falciparum. Means \pm SEM are given. on $P$. berghei. Importantly, the fatty acids showed no toxic effects in mice but, in fact, prevented the malaria-induced anemia.

Morphological studies confirmed the results obtained from the radiometric assay and revealed that fatty acids caused intraerythrocytic degeneration and death of $P$. falciparum. Intraerythrocytic degenerative forms (crisis forms) of malarial parasites were observed as early as 1944 by Taliaferro and Taliaferro (17) in $P$. brasilianum-infected cebus and spider monkeys. Since then, abnormal forms of intraerythrocytic Plasmodium species have been reported in rodents, primates, and hu-

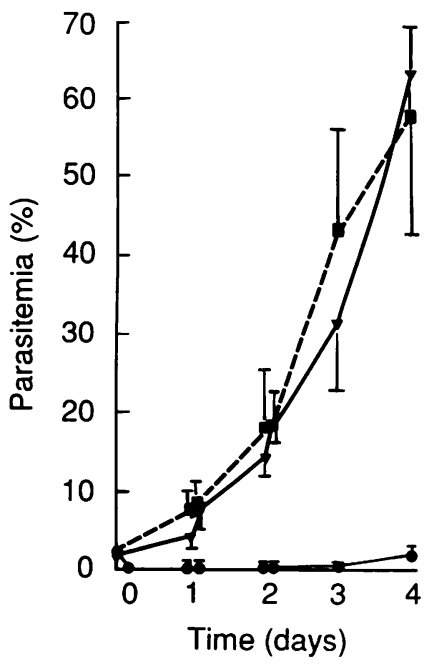

Figure 5. The effect of $\mathrm{C}_{22: 6, \mathrm{n}-3}$ on $P$. berghei infection in mice. Mice were treated with $\mathrm{C}_{22: 6, \mathrm{n}-3}$ in DPPC (•), DPPC alone (ø), or normal saline ( $\mathbf{v})$. Means \pm SEM are given. mans (for review see reference 11). Tumor necrosis factor $\alpha$ (TNF $\alpha$; references $10,18,19$ ), or a combination of TNF $\alpha$ and interferon $\gamma$ with some undefined factors $(5,20)$, has been suggested as candidates for crisis-inducing factors. Under in vitro conditions, we have found no evidence that any of the macrophage and lymphocyte cytokines; TNF $\alpha$; lymphotoxin; interferon $\gamma$; interleukins- $1,-2,-4$, or -8 ; or granulocyte macrophage colony-stimulating factor induce degeneration of intraerythrocytic $P$. falciparum in the presence or absence of complement and antimalarial antibody $(12,13,21)$. Others have suggested a role for molecules such as oxygen-derived reactive species $(4$, 22 ), reactive nitrogen intermediates (23), oxidized polyamines (24), and lipid peroxides $(4,7)$. Our studies suggest that polyunsaturated fatty acids may constitute a crisis-inducing system in $P$. falciparum-infected RBC.

The mature mammalian RBC has negligible lipid metabolism, and Plasmodia cannot form fatty acids by de novo synthesis $(25,26)$. Under the influence of the parasite, host RBC cell membrane is grossly altered in structure and composition. Radiolabeled studies have shown that the uptake of certain fatty acids increases dramatically after the infection with malaria parasites (27-30). Interestingly, malaria infection causes a marked reduction in the unsaturation index of $\mathrm{RBC}$ phospholipids, mainly as a result of the decreases in the amounts of $\mathrm{C}_{22: 6, \mathrm{n}-3}, \mathrm{C}_{20: 4, \mathrm{n}-6}$, and $\mathrm{C}_{18: 2, \mathrm{n}-6}(27)$. Our study shows that when PRBC are exposed to the same fatty acids or their methyl esters or oxidized fatty acids, parasiticidal effects occur, although the basis for the toxicity probably differs according to the state of the fatty acid. Our morphological studies showed that the fatty acids induced death of the parasite and that later these dead 
parasites move (via the parasitophorous vacuole orifice) to the exterior of the RBC. This observation suggests that the site of merozoite invasion, which acts as the orifice of the parasitophorous vacuole, has been damaged by the fatty acids or their derivatives.

It is evident from our studies that oxidized fatty acids are effective in inducing parasiticidal effects of $P$. falciparum. It is also likely that the effect of the parent nonoxidized fatty acid is related to fatty acid oxidation by the parasite or $\mathrm{RBC}$, because antioxidants such as BHT and vitamin E markedly reduce the antimalarial activity of the fatty acids. Moreover, saturated and monounsaturated fatty acids, which are more resistant to oxidative attack, are much less effective than fatty acids with two or more double bonds. The nature of the oxidation products that induce the effect remains unclear. Lipid hydroperoxides (mainly mono- and dihydroxy derivatives) are major products of autooxidation, although a variety of other compounds (including alkanals, hydroxyalkanals, malonaldehyde, polymerized polar derivatives, and even volatile carbonyls) are produced (31). Whether some or all of these products are effective at inducing degeneration of the parasite remains to be determined. The mechanism of action of the active agents is clearly dependent on their structure. Thus, fatty acid hydroperoxides may act by oxidizing reduced glutathione and thereby making the parasite more susceptible to oxidative stress, whereas malonaldehyde is thought to interfere with membrane function through its ability to form cross-linkages between proteins and lipids (4). Recently it has been suggested that certain specific oxidized fatty acid products (e.g., oligomeric prostaglandins, which also inhibit the growth of $P$. falciparum [32]) could act through their ability to bind calcium or inhibited phospholipase or protease activities (33). Whether the oxidation products formed from the various polyunsaturated fatty acids used in our study act in a similar fashion remains to be established. Clearly, further studies with individual compounds are needed to clarify their action.

In vitro experiments of the present study showed that scavengers of reactive oxygen species and antioxidants reduced the fatty acid-induced killing of the parasite. It has been shown that administration of butylated dydroxyanisole, SOD, or catalase reduced cerebral pathology of $P$. berghei ANKA mice (34). Treatment of malaria-infected mice with these scavengers and antioxidants may counteract the fatty acid-mediated killing, if both treatments are given simultaneously. Treatment of mice with fatty acids alone, however, did not aggravate the pathology of malaria, probably related to the marked reduction of parasitemia.

Antimalarial activity of fish oil was relatively low. Fish oils are a source of triglycerides containing $\omega-3$ fatty acids, and the preparation used in this study contained $18 \% \mathrm{C}_{20: 5, \mathrm{n}-3}$ and $12 \%$ $\mathrm{C}_{22: 6, \mathrm{n}-3}$. It is possible that the remaining constituents of the fish oil counteracted the effects of $\mathrm{C}_{20: 5, \mathrm{n}-3}$ and $\mathrm{C}_{22: 6, \mathrm{n}-3}$. Alternatively, the triglycerides containing $\mathrm{C}_{20: 5, \mathrm{n}-3}$ and $\mathrm{C}_{22: 6, \mathrm{n}-3}$ may not be available to the parasite, because of the relatively larger size of the molecule.

The data presented in this paper provide new strategies that can be explored for the treatment of malaria at a time when new antimalarials are in demand. These fatty acids, in addition to being able to act directly on the parasites, may also activate neutrophils (35) and other effector cells for increased killing of malarial parasites.

\section{Acknowledgments}

We thank Timothy Jaeger for excellent technical assistance.

This investigation received financial support from United Nations Development Programme/World Bank/World Health Organization Special Programme for Research and Training in Tropical Diseases (TDR), and the Adelaide Children's Hospital Research Foundation.

\section{References}

1. Anonymous. 1989. Malaria. In Tropical Diseases Progress in International Research, 1987-1988. Ninth Programme Report, UNDP/World Bank/WHO, Geneva. 43-49.

2. Stevenson, M. M. 1990. Preface. In Malaria: Host Responses to Infection. M. M. Stevenson, editor. CRC Press, Inc., Boca Raton, FL.

3. Clark, I. A., N. H. Hunt, G. A. Butcher, and W. B. Cowden. 1987. Inhibition of murine malaria (Plasmodium chabaudi) in vivo by recombinant interferon- $\gamma$ or tumor necrosis factor, and its enhancement by butylated hydroxyanisole. J. Immunol. 139:3493-3496.

4. Allison, A. C., and E. Eugui. 1983. The role of cell-mediated immune responses in resistance to malaria, with special reference to oxidant stress. Annu. Rev. Immunol. 1:361-392.

5. Mendis, K. N., T. de S. Naotunne, N. D. Karunaweera, G. D. Guidice, G. E. Grau, and R. Carter. 1990. Anti-parasite effects of cytokines in malaria. Immunol. Lett. 25:217-220.

6. Stevenson, M. M., and E. Ghadirian. 1989. Human recombinant tumor necrosis factor alpha protects susceptible $\mathbf{A} / \mathbf{J}$ mice against lethal Plasmodium chabaudi infection. Infect. Immun. 51:3936-3939.

7. Rockett, K. A., G. A. Targett, and J. H. L. Playfair. 1988. Killing of bloodstage Plasmodium falciparum by lipid peroxides from tumor necrosis serum. Infect. Immun. 56:3180-3183.

8. Clark, I. A., G. A. Butcher, G. D. Buffington, N. H. Hunt, and W. B. Cowden. 1986. Toxicity of certain products of lipid peroxidation to the human malaria parasite Plasmodium falciparum. Biochem. Pharmacol. 36:543-546.

9. Jensen, J. B., B. T. Boland, and M. A. Akood. 1982. Induction of crisis forms in cultured Plasmodium falciparum with immune sera from Sudan. Science (Wash. DC). 216:1230-1233.

10. Taverne, J., J. Tavernier, W. Fiers, and J. H. L. Playfair. 1987. Recombinant tumour necrosis factor inhibits malaria parasites in vivo but not in vitro. Clin. Exp. Immunol. 67:1-4.

11. Jensen, J. B. 1990. Malaria crisis forms, intraerythrocytic development derangement. In Malaria: Host Responses to Infection. M. M. Stevenson, editor. CRC Press, Inc., Boca Raton, FL. 109-127.

12. Kumaratilake, L. M., A. Ferrante, and C. M. Rzepczyk. 1990. Tumor necrosis factor enhances neutrophil-mediated killing of Plasmodium falciparum. Infect. Immun. 58:788-793.

13. Kumaratilake, L. M., A. Ferrante, and C. M. Rzepczyk. 1991. The role of T lymphocytes in immunity to Plasmodium falciparum: enhancement of neutrophil-mediated parasite killing by lymphotoxin and interferon gamma, comparisons with tumor necrosis factor effects. J. Immunol. 146:762-767.

14. Lijana, R. C., and M. C. Williams. 1979. Tetramethylbenzidine-a substitute for benzidine in hemoglobin analysis. J. Lab. Clin. Med. 94:266-276.

15. Kim, R. S., and F. S. LaBella. 1987. Comparison of analytical methods for monitoring antioxidation profiles of authentic lipids. J. Lipid Res. 28:11101117.

16. Trager, W., and J. B. Jensen. 1976. Human malaria parasites in continuous culture. Science (Wash. DC). 193:673-675.

17. Taliaferro, W. H., and L. G. Taliaferro. 1944. The effect of immunity on the asexual reproduction of Plasmodium brasilianum. J. Infect. Dis. 75:1-32.

18. Haidaris, C. G., D. Haynes, M. S. Meltzer, and A. C. Allison. 1983. Serum containing tumour necrosis factor is cytotoxic for the human malaria parasite Plasmodium falciparum. Infect. Immun. 42:385-393.

19. Clark, I. A., N. H. Hunt, G. A. Butcher, and W. B. Cowden. 1987. Inhibition of murine malaria Plasmodium chabaudi in vivo by recombinant interferon$\gamma$ or tumor necrosis factor and its enhancement by butylated hydroxyanisole. $J$. Immunol. 139:3493-3996.

20. Naotunne, T. de S., N. D. Karunaweera, G. D. Giudice, M. V. Kularatne, G. E. Grau, R. Carter, and K. N. Mendis. 1991. Cytokines kill malaria parasites during infection crisis: extracellular complementary factors are essential. J. Exp. Med. 173:523-529.

21. Ferrante A., L. M. Kumaratilake, C. M. Rzepczyk, and J.-M. Dayer. 1990. Killing of Plasmodium falciparum by cytokine activated effector cells (neutrophils and macrophages). Immunol. Lett. 25:179-188.

22. Dockrell, H. M., and J. H. L. Playfair. 1984. Killing of Plasmodium yoelii by enzyme-induced products of the oxidative burst. Infect. Immun. 43:451-454

23. Rockett, K. A., M. M. Awburn, W. B. Cowden, and I. A. Clark. 1991. 
Killing of Plasmodium falciparum in vitro by nitric oxide derivatives. Infect. Immun. 59:3280-3283.

24. Ferrante, A., C. M. Rzepczyk, and A. C. Allison. 1983. Polyamine oxidase mediates intra-erythrocytic death of Plasmodium falciparum. Trans. $R$. Soc. Trop. Med. Hyg. 77:789-791.

25. Holz, G. G., Jr. 1977. Lipids and the malarial parasite. Bull. WHO. $55: 2-3$

26. Sherman, I. W. 1979. Biochemistry of Plasmodium (malarial parasites). Microbiol. Rev. 43:453-495.

27. Hsiao, Li. Li., R. I. Howard, M. Aikawa, and T. F. Taraschi. 1991. Modification of host cell membrane lipid composition by the intra-erythrocytic human malaria parasite Plasmodium falciparum. Biochem. J. 274:121-132.

28. Rock, R. C. 1971. Incorporation of ${ }^{14} \mathrm{C}$-labelled fatty acids into lipids of rhesus erythrocytes and Plasmodium knowlesi in vitro. Comp. Biochem. Physiol. 40B:893-906.

29. Cenedella, R. J. 1968. Lipid synthesis in vivo from 14C-oleic acid and 6-3H-glucose by intraerythrocytic Plasmodium berghei. Mil. Med. 134:10451055.

30. Vial, H. J., M. J. Thuet, J. L. Broussal, and J. R. Philippot. 1982. Phospholipid biosynthesis by Plasmodium knowlesi-infected erythrocytes: the incorpora- tion of phospholipid precursors and the identification of previously undetected metabolic pathways. J. Parasitol. 68:379-391.

31. Esterbauer, H., K. H. Cheeseman, M. V. Dianzani, G. Poli, and T. F. Slater. 1982. Separation and characterization of the aldehyde products of lipid peroxidation stimulated by ADP- $\mathrm{Fe}^{2+}$ in rat liver microsomes. Biochem. $J$. 208:129-140.

32. Ohnishi, S. T., N. Ohnishi, Y. Oda, and M. Katsuoka. 1989. Prostaglandin derivatives inhibit the growth of malarial parasites in mice. Cell Biochem. Func. 7:105-109.

33. Ohnishi, S. T., K. K. Sadanaga, M. Katsuoka, and W. P. Weidanz. 1989. Membrane-acting drugs on Plasmodium species and sickle cell erythrocytes. Mol. Cell. Biochem. 91:159-165.

34. Thumwood, C. M., N. H. Hunt, W. B. Cowden, and I. A. Clark. 1989. Antioxidants can prevent cerebral malaria in Plasmodium berghei-infected mice. Br. J. Exp. Pathol. 70:293-303.

35. Poulos, A., B. S. Robinson, A. Ferrante, D. P. Harvey, S. J. Hardy, and A. W. Murray. 1991. Effect of 22 to 32 carbon n-3 polyunsaturated fatty acids on superoxide formation in human neutrophils. Synergism of docosahexanoic acid with phorbol myristate acetate and f-met-leu-phe. Immunology. 73:102-108. 